\title{
Pseudo Bulbar Palsy: A Rare Cause of Extubation Failure
}

Sir,

Extubation Failure (EF) following weaning trials is a well known entity in Intensive Care Units (ICUs). The varied prevalence $(2 \%-25 \%)$ of EF depends on the population studied and the time frame $(24-72 \mathrm{~h})$ included for analysis. ${ }^{[1]}$ Airway edema and nonresolution of the primary disease are a common cause. Swallowing dysfunction as a cause of EF may at times account for more than $50 \%$ of patients. ${ }^{[1]}$ We report an unusual presentation of lacunar stroke with pseudobulbar palsy presenting with EF.

An 80-year-old woman a known case of hypertension and Type 2 diabetes mellitus with good premorbid functional status, presented with 10 days history of intermittent fever associated with chills and rigor, nausea, and episodes of loose stools. History also included increased urinary urgency and frequency and urinary incontinence. Four days after the illness, she developed shortness of breath. She was referred to our ICU on the $8^{\text {th }}$ day of her illness.

In our initial assessment, she was conscious, oriented, and cooperative. Her limb power as assessed both at distal and at proximal joints were $5 / 5$, with flexor plantars and normal deep tendon reflexes. She had dysphonia at presentation. She had distressed breathing, bilateral basal crepts on auscultation, shock with cold peripheries, and ongoing noradrenaline dose of $0.2 \mathrm{mics} / \mathrm{kg} / \mathrm{min}$. She was managed as per the ICU protocols. She was weaned off the ventilator, and after a successful spontaneous breathing trial, she was extubated. Within $2 \mathrm{~h}$ of extubation, she had stridor, drooling of saliva, and dysphagia. Airway edema was suspected. Measures taken to reduce edema included adrenaline nebulizations and systemic steroid, to which she did not show any improvement. She was re-intubated and subsequently tracheostomized. Upper airway bronchoscopy was done which was suggestive of hypotonic pharyngeal muscle with no vocal cord movements. Indirect laryngoscopy (IDL) performed by ears, nose, and throat surgeon validated the above findings [Figure 1]. Further

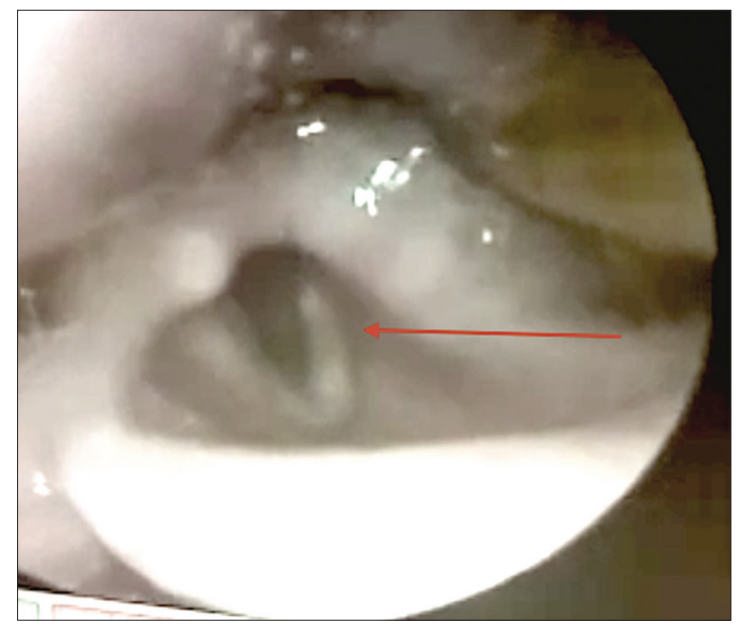

Figure 1: Indirect laryngoscopy showing vocal cord palsy

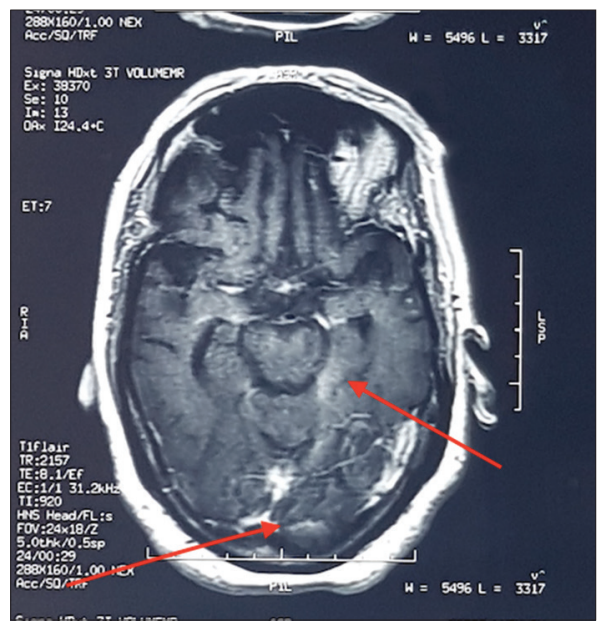

Figure 2: Hyperintensities noted in centrum semi ovale, thalmi, cortical areas in T2 flair

neurological examination revealed a brisk jaw jerk reflex with bulbar weakness clinically evident as swallowing dysfunction. 


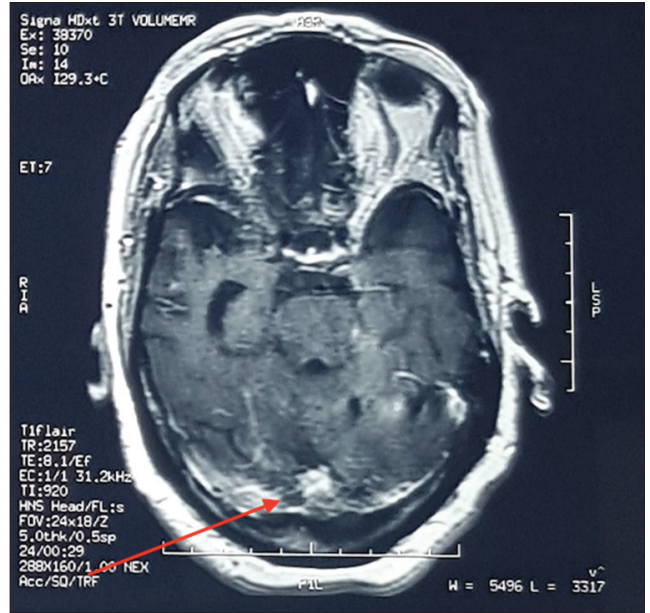

Figure 3: Hyperintensities noted in bilateral cortical and subcortical areas in T2 flair

Her laboratory parameters including sodium were within normal limits throughout her stay in ICU. Magnetic resonance imaging (MRI) brain was done which was suggestive of multiple foci of confluent long hyperintensities in bilateral cortical and subcortical areas [Figures 2 and 3]. After 2 weeks of ICU stay, she was discharged with a tracheostomy tube in situ, and routine tracheostomy care was taught to the relatives. She has been advised for a 2 weekly follow-up. Informed consent was taken from the relatives of the patient.

The isolated pseudo bulbar weakness with no limb weakness is a rare entity with only a few reported cases. ${ }^{[2,3]}$ Unilateral lacunar stroke limited to corticonuclear pathways may be asymptomatic. When symptomatic, unilateral pathway damage usually produces only lower facial weakness, and mostly without significant limb weakness. ${ }^{[4]}$ Other symptoms of dysarthria, drooling, speech abnormities, nasal regurgitation, and emotional liability are common. ${ }^{[3]}$ Our case report highlights an atypical presentation of stroke as a cause of EF. A high clinical suspicion, vocal cord palsy on IDL and microangiopathic changes in MRI, confirmed our diagnosis.

\section{Declaration of patient consent}

The authors certify that they have obtained all appropriate patient consent forms. In the form the patient(s) has/have given his/her/their consent for his/her/their images and other clinical information to be reported in the journal. The patients understand that their names and initials will not be published and due efforts will be made to conceal their identity, but anonymity cannot be guaranteed.

\section{Financial support and sponsorship Nil.}

\section{Conflicts of interest}

There are no conflicts of interest.

Ritu Singh, Monalisa Nayak, Sunil Kumar Jena, Afzal Azim

Department of Critical Care Medicine, Sanjay Gandhi Postgraduate Institute of Medical Sciences, Lucknow, Uttar Pradesh, India

Address for correspondence: Dr. Afzal Azim, Department of Critical Care Medicine, Sanjay Gandhi Postgraduate Institute of Medical Sciences, Lucknow, Uttar Pradesh, India. E-mail: draazim2002@gmail.com

\section{REFERENCES}

1. Rothaar RC, Epstein SK. Extubation failure: Magnitude of the problem, impact on outcomes, and prevention. Curr Opin Crit Care 2003;9:59-66.

2. Puvanendran K, Wong PK, Ransome GA. Syndrome of Dejerine's fourth reich. Acta Neurol Scand 1978;57:349-53.

3. Huang CY, Broe G. Isolated facial palsy: A new lacunar syndrome J Neurol Neurosurg Psychiatry 1984;47:84-6.

4. Besson G, Bogousslavsky J, Regli F, Maeder P. Acute pseudobulbar or suprabulbar palsy. Arch Neurol 1991;48:501-7.

This is an open access journal, and articles are distributed under the terms of the Creative Commons Attribution-NonCommercial-ShareAlike 4.0 License, which allows others to remix, tweak, and build upon the work non-commercially, as long as appropriate credit is given and the new creations are licensed under the identical terms.

\begin{tabular}{|l|l|}
\hline \multicolumn{3}{|c|}{ Access this article online } \\
\hline Quick Response Code: & Website: \\
\hline & www.ijccm.org \\
\hline
\end{tabular}

How to cite this article: Singh R, Nayak M, Jena SK, Azim A. Pseudo bulbar palsy: A rare cause of extubation failure. Indian J Crit Care Med 2018;22:620-1.

C 2018 Indian Journal of Critical Care Medicine | Published by Wolters Kluwer - Medknow 